\title{
ANALISIS SISTEM KERJA ARUS LISTRIK PADA KETAHANAN DIRRECT CURRENT (DC) PADA PERSONAL COMPUTER
}

\author{
SUDARMAJI ${ }^{* 1}$ \\ ${ }^{*}$ Dosen Program Diploma 3 Manajemen Informatika \\ Universitas Muhammadiyah Metro \\ E-mail: dharmaji_1974@yahoo.com
}

\begin{abstract}
Sistem power supply merupakan sebuah sistem yang terdiri atas beberapa bagian rangkaian dengan fungsi tersendiri di satukan membentuk sistem kerja sebuah penyedia daya listrik. Menurut definisinya sebuah power supply merupakan penyedia sumber arus tegangan DC dengan merubah dari tegangan AC. Analisis berikut ini merupakan langkah-langkah dalam menentukan letak kerusakan power supply, indikasi yang dimiliki adalah Power Supply bekerja tetapi tidak berjalan pada sistem komputer. Banyak sebab dalam permasalahan ini sehingga sistem komputer tidak dapat bekerja dengan power supply tersebut. Pemeriksaan lebih ditekankan dalam hubungan power supply dengan sistem komputer. Sebab sebab komputer tidak bekerja diteliti dan dianalisa untuk menentukan letak kesalahan pada power supply.
\end{abstract}

Keywords: Power Supply, DC, AC

\section{PENDAHULUAN}

\subsection{Latar Belakang}

Power Supply merupakan sebuah sistem yang menyediakan sumber daya DC (Dirrect Current) atau arus searah, diperoleh dengan jalan merubah arus bolak balik AC menjadi arus searah dan menstabilkan tegangan keluarannya menurut kebutuhan sebuah sistem elektronik. Menurut sistem regulator, tipe sebuah power supply dibagi kedalam dua jenis yaitu Linear dan Switching. Power Supply tipe switching menjadi semakin populer pemakaiannya karena tipe ini memberikan penyediaan daya DC yang efisiensi dan densitas dayanya sangat tinggi dibandingkan dengan tipe linier. Teknologi penyediaan daya DC melalui tipe switching sebenarnya bukan merupakan hal yang baru.

\section{DASAR PENGERTIAN DC (POWER SUPPLY) PADA PC}

\subsection{Power Supply AT}

Power Supply jenis ini digunakan pada komputer jenis lama, merupakan jenis power dengan keluaran soket 12 PIN pada Motherboard, banyak digunakan pada komputer sebelum Pentium II. Kelemahan power supply jenis ini pada pengaturan sistem power management yaitu tidak dapat langsung mati ketika sistem pada komputer di matikan (shutdown). Tetapi keuntungan pada power supply jenis ini tidak ada konsumsi daya saat power supply dimatikan.

\subsection{Power Supply ATX}

Power Supply jenis ini memberikan performa yang sangat baik untuk sebuah sistem power management pada sistem komputer. Dengan tersedianya sebuah pin switch elektronik(PS_ON) proses menghidupkan maupun mematikan sistem ini dapat dikontrol dengan sebuah piranti lunak (software) melalui Mother Board. Kelemahannya adalah dengan posisi mati tetapi aliran listrik masih terhubung power supply jenis ini tidak benar-benar dalam keadaan mati, masih ada pemakaian daya walaupun sangat kecil.

Sistem power supply merupakan sebuah sistem yang terdiri atas beberapa bagian rangkaian dengan fungsi tersendiri di satukan membentuk sistem kerja sebuah penyedia daya listrik. Menurut definisinya sebuah power supply merupakan penyedia sumber arus tegangan DC dengan merubah dari tegangan AC. Namun pada kenyataannya pada sebuah sistem power supply khususnya jenis ATX, proses dilakukan adalah sebagai berikut:

1) Pertama, Tegangan AC dari sumber arus tegangan listrik diubah menjadi tegangan DC tegangan tinggi.

2) Kedua, Tegangan tinggi DC tersebut diubah menjadi tegangan AC gelombang kotak persegi kembali oleh rangkaian Switching tetapi menjadi lebih rendah.

3) Ketiga, tegangan AC gelombang kotak persegi rendah tersebut kemudian disearahkan kembali menjadi tegangan DC rendah. 


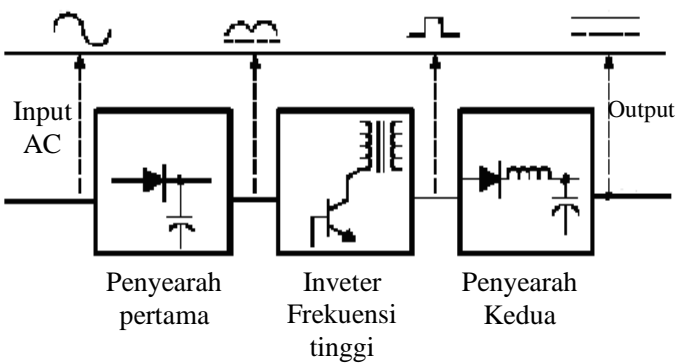

Gambar 1. Blok diagram kerja power supply ATX

Selain ketiga proses penting diatas, sebuah sistem power supply ATX melakukan pekerjaanpekerjaan sebagai berikut:

1) melakukan filter terhadap masukan tegangan AC dan keluaran tegangan DC;

2) menstabilkan keluaran tegangan DC dengan ada atau tidaknya beban;

3) memproteksi dari proses naiknya tegangan berlebihan

4) penyediaan sebuah sarana penyambungan atau pemutusan sumber tegangan keluaran dengan menyediakan sistem saklar elektronik.

5) Memberikan sinyal pemberitahuan kepada komputer mengenai status

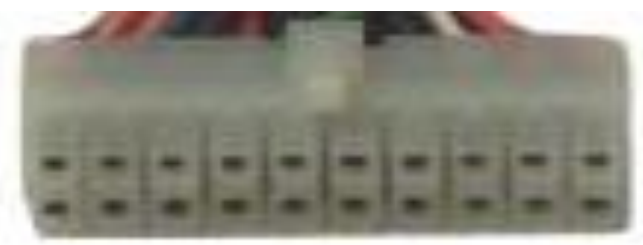

Gambar 2. Aliran Arus dan Perubahan tegangan pada reset otomatis (Paulus Andi Nalwan, Elek Media Komputindo, Jakarta 2003)

Sedangkan gambar dibawah ini merupakan layout konektor pada motherboard, untuk memeriksa setiap pin pada konektor ini dapat digunakan gambar di bawah ini sebagai pedoman agar tidak terjadi kesalahan pengukuran.

\subsection{Connector Pheripheral Komputer}

Maksud dari konektor peripheral adalah konektor keluaran dari power supply dan disediakan untuk supply peralatan pendukung sistem komputer karena tidak dimungkinkan untuk mengambil langsung dari motherboard.
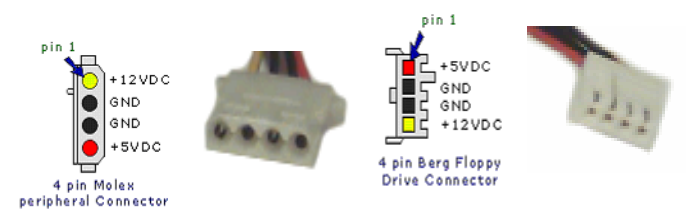

Gambar 3. konektor untuk harddisk, CD Drive
Dibawah ini merupakan gambaran terperinci dari model Power Supply ATX yang digunakan pada sistem komputer, dibangun berdasarkan blokblok diagram yang mempunyai fungsi dan tugas sendiri.

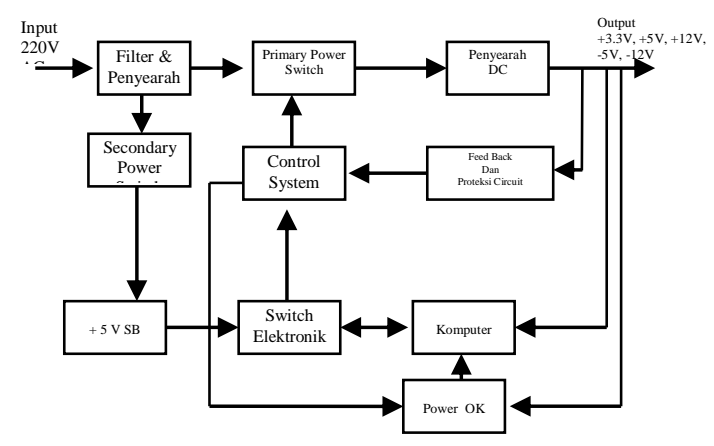

Gambar 4. Blok Diagram Sistem DC Power Supply

\section{DASAR TEORI}

Langkah pertama dalam mendiagnosa Power Supply adalah menentukan ada tidaknya tegangan yang keluar. Bagaimana menentukan bahwa power supply itu hidup? Apakah cukup diketahui hanya dengan melihat putaran kipas dan bergeraknya motor keatas, atau melihat lampu kecil menyala pada di depan casing komputer atau mendengar suara suatu tanda bunyi? Jika kasus sistem sangat panas seketika dihubungkan, kita dapati bahwa kesalahan pada grounding atau hubung singkat. Jika pendengaran kita tidak bagus, kita dapat selalu memeriksa untuk melihat jika kipas power supply menghasilkan angin sejuk berarti power supply tersebut bekerja.

Kasus kasus berikut ini hanya merupakan diagnosa dalam menentukan kerusakan tidak bekerjanya sistem komputer karena masalah power supply sebagai penyedia arus atau disebabkan masalah kerusakan sistem komputer. Untuk mendiagnosa permasalahan jika power supply tidak bekerja, langkah pertama adalah mengecek tegangan jaringan listrik ada atau tidak, kita tidak perlu menggunakan alat pengecek semacam multimeter, cukup kabel tegangan listrik tersebut dihubungkan dengan lampu atau radio jika lampu atau radio tersebut menyala berarti jaringan listriknya bagus.

Jika jaringan listrik terputus, jangan mengasumsikan terminal power tersebut bagus, karena pada terminal yang lain diketahui lampu dapat menyala. Banyak pada terminal jaringan listrik ditemui terdapat satu atau lebih terminal yang rusak.

Terminal listrik utama jarang mengalami kerusakan, tetapi sangat mungkin pada konektor female power supply dibagian belakang soketnya mengendur. Kita harus meyakinkan kedua ujung dari kabel power tertancap penuh pada terminal AC outlet power supply.Ketika kita menekan 
power switch tetapi tidak dengan seketika komputer shut down, ini merupakan hal yang normal pada sistem ATX, aksi pada pada power supply tersebut di program dan dikontrol melalui setting CMOS pada sistem BIOS.

Operasi standard pada kebanyakan switch power supply memerlukan bantuan kita untuk menekan saklar dalam 3 sampai 5 detik sebelum sistem power supply akan dimatikan. Hal ini mengijinkan penggunaan switch power untuk menghidupkan kembali power supply komputer pada posisi mode " Sleep "atau "Standbay", tergantung pada pengaturan power management CMOS Setup. Jika permasalahan yang ditemui sistem operasi komputer tidak dapat mematikan power supply dengan perintah shut down, mungkin hal itu disebabkan kurang tepatnya pengaturan power management atau cacatnya file pada sistem operasi. Periksa kerja switch dengan multimeter (baik digital maupun analog) pada saat posisi terhubung dan terputus.

Pada seluruh sistem ATX, switch power ternyata hanya sebuah switch logika yang mengacu pada motherboard, yang mana sebuah gerakan menekan untuk menghidupkan power supply arus listrik selalu tersedia, untuk memerintahkan power supply bekerja penuh. Jika bentuk power supply dengan kabel besar dihubungkan dengan switch besar pada box power supply, dengan empat sambungan kabel, power supply tersebut merupakan power supply AT model lama dan berpotensial mematikan tegangan listrik jika dilakukan penekanan pada switch tersebut. Prosedur ini jangan di terapkan pada Power Supply AT yang sudah usang.

Ketika bekerja pada sistem ATX dan tidak mempunyai multimeter, hubungkan dua pin pada motherboard dengan menggunakan obeng, dimana switch logika pada panel depan harus dipasang, dan dapat dilihat jika sistem berfungsi. Power supply akan mengalami kegagalan bekerja jika konektor power ke motherboard tidak terhubung. Langkah yang harus diambil adalah memeriksa konektor 20 pin ATX kearah motherboard dan tambahan lainnya pada konektor power motherboard, seperti $12 \mathrm{~V}$ power supply untuk sistem Pentium 4 dan CORE 2, apakah sudah benar-benar terhubung dan benar-benar mantap pada dudukannya.

Pengancing mekanik untuk standard konektor ATX Power Supply sudah benar-benar diperhitungkan. Kita dapat menekan pada pengancing pada bagian atas melepaskan pada bagian bawah. dimana titik pada konektor sudah dilepaskan dengan hampir tidak ada tenaga yang diperlukan, harus terdengar atau dirasakan bunyi klik pada pengancing konektor power supply. Tegangan $5 \mathrm{~V}$ pada pin 9 (VSB) selalu tersedia ketika tegangan listrik di tancapkan pada power supply. Pin konektor power supply ini pada berbagai circuit PC selalu bekerja bahkan ketika komputer dimatikan, seperti untuk keperluan“" Wake on Modem ( menghidupkan melalui modem)" atau "Wake on LAN (menghidupkan melalui Jaringan Komputer)".

Ini selalu menjadikan alasan kenapa jangan pernah meninggalkan pekerjaan pada komputer dengan kabel power masih terhubung, kecuali kita selalu ingat untuk mematikan dengan menekan saklar power setiap kali. Hidupnya power ini merupakan supplay untuk slot adapter, jadi lakukan pergantian kabel power untuk motherboard yang dapat mengakibatkan kerusakan motherboard atau slot. Saat komputer terhubung dengan monitor, apakah layar dapat menyala atau ditampilkan pesan "Please connect monitor" atau "No Video Signal detected" diartikan "No" jawaban dari dari kasus ini.

Jika power supply bekerja, tetapi tidak dapat menampilkan tulisan pada layar, matikan power supply dan coba hidupkan kembali komputer. Harus dilakukan penekanan pada power switch untuk lima detik atau lebih sebelum sistem power supply kembali mati. Jika kegagalan pada proses mematikan power supply, dapat dilakukan dengan mematikan switch power supply dibelakang atau mencabut kabel power dari jaringan listrik. Sebuah komputer yang melakukan proses booting perlu dicoba sebanyak dua atau tiga kali hampir bisa dipastikan mengalami kerusakan pada rangkaian power good pada power supply.

Kehadiran sinyal power good memberitahukan kepada motherboard bahwa power supply telah stabil, ketika ketidak hadiran sinyal ini memberitahukan kepada motherboard untuk secara otomatis melindungi diri (memproteksi). Kemungkinan power supply tidak akan bekerja dengan standar power supply ATX yang seperti ini. Penyalaan ulang (booting) sebanyak dua kali setiap waktu menghidupkan komputer bukan merupakan situasi yang ideal, jadi kecuali ditinggalkan seluruhnya, dengan membeli power supply dengan kualiatas tinggi, sesuai dengan rekomendasi pembuat motherboard.

Kode Tanda bunyi (beep) merupakan bagian dari rutinitas Power On Self Test (POST) sebuah komputer. Tanda bunyi sebanyak satu kali artinya bahwa sistem telah melawati pengujian dan BIOS mempercayai bahwa CPU dan Vidoe grafik serta memori berfungsi sebagaimana mestinya. Keseluruhan kode tanda bunyi merujuk pada masing-masing pembuat BIOS dan merk sistemnya, tetapi berulang-ulangnya tanda bunyi yang pelan mengindikasikan RAM bermasalah, jadi matikan komputer dan pasang ulang memori modul. Terulangnya tanda bunyi, antara 3 sampai 9 kali tanda bunyi panjang, kerusakan sering terjadi pada video grafik, maka cabut kabel power 
dan coba kembali dengan memasang ulang video adapter. Jika tanda bunyi terjadi bersamaan dengan tampilnya layar monitor, suka atau tidak suka masalah terdapat pada power supply terkait. Proses pencarian kesalahan pada motherboard, RAM dan CPU merupakan kesalahan diagnosa. Jika tidak terdapat tanda bunyi, yakinkan pada dudukan speaker telah terpasang dengan benar dan hidupkan kembali komputer untuk mengetahui tanda bunyinya.

Jika pada motherboard tidak terdapat titik sambungan untuk dudukan speaker di dekat switch power dan bidang LED, hal tersebut kemungkinan merupakan sistem kerja sebuah piezoelectric speaker terintegrasi. Jika baru-baru ini ditambahkan beberapa komponen baru pada sistem komputer, hal tersebut dapat saja menjadi kemungkinan terbesar masalah power supply atau menyebabkan konsleting (hubung singkat) rangkaian.

Saat komputer dihidupkan, akan selalu terdengar suara berputarnya motor pada harddisk, dan pada proses baca tulis atau pencarian data. Jika power supply bekerja, tetapi tidak terdengar suara berputarnya harddisk, periksa apakah kabel power supply ke harddisk tersebut sudah terpasang. Jika power supply tidak dapat bekerja, lepaskan seluruh perangkat hard drive (Harddisk,CDROM, Floppy Disk dll) dan hidupkan kembali komputer setelah perubahan ini dilakukan. Jika power supply bekerja, kita dapati salah satu dari hard drive tersebut menjadi penyebab tidak bekerja power supply.

Jika setelah semua hard drive dilepaskan tetapi power tidak dapat bekerja mulailah dengan mencabut adapter-adapter yang terpasang pada motherboard, satu persatu, sampai hidupnya layar. Jangan lupa melepaskan kabel power jaringan listrik sebelum melepaskan adapter-adapter tersebut, kemudian hubungkan kembali dan nyalakan power supply. Jika power dapat bekerja, pasang kembali seluruh adapter kecuali yang terakhir dilepaskan sebelum power supply bekerja. Jika power supply bekerja, coba hubungkan kembali adapter terakhir yang dilepaskan pada slot yang berbeda. Jika ditemukan sebuah adapter yang benar-benar menghalangi sistem power supply bekerja, segera lakukan penggantian.

Untuk diingat bila adapter bermasalah tersebut merupakan video adapter, tipe dari video grafik tersebut adalah AGP, yang mana motherboard hanya memiliki satu slot, hal ini menyebabkan kesalahan pada AGP slot. Kemungkinan yang lain adalah pengunci AGP adapter tidak terpasang sempurna sehingga terjadi hubung singkat. Setelah satu persatu hard drive dan adapter dilepaskan tetapi tidak juga power supply bekerja, salah satu kemungkinan kesalahan ada pada motherboard yaitu hubung singkat.
Bongkar motherboard dan periksa dudukan motherboard pada lokasi dipasangnya baut pada lokasi yang salah atau terlepasnya baut disekitarnya. Normalnya, sebuah hubung singkat ditandai dengan adanya bau terbakar dan sebuah kerusakan pada motherboard, kadangkala kerusakan pada beberapa komponen yang terpasang (memory, prosessor atau adapter) yang awal baik.

Dan pada beberapa bagian, dapat di saksikan dimana komponen yang rusak dengan kehadiran bekas terbakar atau bau menyengat seperti asap rokok dari komponen yang terbakar, meskipun kejadian ini pada saat kasing tertutup, bau terbakar tersebut dapat keluar setiap saat. Pembahasan pada bagian ini lebih ditekankan pada pencarian kerusakan pada power supply setelah dipastikan tidak ada masalah pada sistem komputer.

Setelah prosedur pengecekan pada sistem komputer memastikan bahwa permasalahan ada pada power supply maka langkah-langkah berikut ini dilaksanakan untuk lebih memusatkan letak masalah dalam power supply. Langkah-langkah sistematis dilakukan untuk mencari kerusakan sebuah power supply dengan kondisi tidak bekerja sama sekali ketika diberikan sumber tegangan listrik.

Di luar pembicaraan apakah itu merupakan langkah yang efisien atau tidak mengingat harga untuk sebuah unit power supply lebih murah dibanding ongkos untuk memperbaiki kerusakannya. Tetapi tujuan dari proses perbaikan tersebut adalah faktor waktu dalam melaksanakan perbaikan menjadi penting. Pemeriksaan sebuah power supply tidak bekerja, sebelum membuka sebuah box power supply adalah mengukur besarnya tegangan pada kaki pin 9 konenktor untuk motherboard (+VSB). Dengan menggunakan multimeter digital harus terdapat tegangan $+5 \mathrm{~V}$, jika tidak terdapat tegangan tersebut sudah dipastikan kerusakan merupakan rangkaian dari secondary power switch, cabut kabel power tegangan listrik.

Langkah selanjutnya adalah memeriksa tegangan pada kaki kolektor ( drain untuk MOSFET) transistor secondary power power switch, harus ditunjukan tegangan DC berkisar antara 260 - 300 VDC (tegangan listrik dialirkan). Jika tidak di temukan tegangan pada kaki kolektor sudah dapat dipastikan terdapat kerusakan pada rangkaian filter noise dan penyearah. Jika di temukan tegangan pada kaki kolektor, periksa tegangan pada kaki basis transistor power switch. Harus terdapat tegangan DC bekisar antara 0,3 1,0 V sebagai bias panjar pada untuk transistor tersebut. Tidak ditemukannya bias panjar tersebut kerusakan hampir bisa dipastikan pada dua hal yaitu putusnya resistor panjar bias transistor atau 
terjadi hubung singkat pada transistor tersebut. Lakukan pengukuran dengan mengangkat komponen dari PCB dan pastikan kerusakan pada kedua komponen tersebut kemudian lakukan pergantian. Jika terdapat panjar bias pada transistor tetapi secondary power supply tetap tidak bekerja kemungkinan besar kerusakan pada rangkaian pembangkit frekuensi switching.

Langkah terakhir adalah memeriksa setiap komponen pembangkit frekuensi tersebut sehingga ditemukan kerusakannya.Langkah ini diambil jika didapati tegangan pada keluaran secondary power switch (+VSB) ada tetapi power supply tidak dapat mengeluarkan tegangan keluarannya. Periksa pin 14 pada konektor power supply untuk motherboard. Harus dijumpai tegangan sebesar +5 $\mathrm{V}$ pada kaki pin ini dengan menghubungkan power supply dengan tegangan listrik. Jika ada tegangan pada pin PS_ON ini dipastikan kerusakan pada rangkaian pembangkit saklar elektronik ini.

Langkah mencari letak kerusakan saklar elektronik adalah dengan memeriksa tegangan sumber untuk pembangkit rangkaian saklar elektronik ini. Dengan berdasarkan diagram power supply pada pembahasan ini diketahui rangkaian saklar elektronik memanfaatkan 2 buah transistor Q 10 dan Q1. langkah pertama memeriksa tegangan pada kaki emitor Q1 terdapat tegangan atau tidak bila ada periksa tegangan pada kaki basis Q1 harus ada tegangan yang besarnya mendekati tegangan pada kaki emitor Q1. Tidak adanya tegangan pada kaki basis transistor Q1 menandakan terjadi kerusakan pada transistor tersebut.

Analisis berikut ini merupakan langkahlangkah dalam menentukan letak kerusakan power supply, indikasi yang dimiliki adalah power supply bekerja tetapi tidak berjalan pada sistem komputer. Banyak sebab dalam permasalahan ini sehingga sistem komputer tidak dapat bekerja dengan power supply tersebut.

Pemeriksaan lebih ditekankan dalam hubungan power supply dengan sistem komputer. Sebab sebab komputer tidak bekerja diteliti dan dianalisa untuk menentukan letak kesalahan pada power supply.

\section{KESIMPULAN}

Dalam menganalisa sistem power supply ini, rangkaian dipecah-pecah ke dalam blok-blok rangkaian menurut fungsinya dalam sebuah power supply. Agar diperoleh gambaran lengkap sebuah sistem power supply tiap-tiap pembahasan mengenai blok-blok ini diuraikan sebagai pembahasan secara sistematis berdasarkan fungsi rangkaian dalam power supply.

Setelah disearahkan oleh penyearah tegangan tinggi DC tersebut akan ditampung sementara pada kapasitor perata, sehingga perubahan kerut-kerut dari penyearah dapat kurangi bahkan dihilangkan. Kebutuhan rangkaian switching akan terbabasnya supply tegangan terbebas dari desah-desah tidak diinginkan mutlak diperlukan agar tidak mengganggu proses bekerja power supply tersebut.

\section{REFRENSI}

1) Elex Media Komputindo, 1996.Panduan Belajar Elektronika Digital / Ian Robertson Sinclair; Alih Bahasa: Suryawan.-- Cet. 2, Jakarta.

2) Yogyakarta: Andi, 2002.Electronic government: strategi pembangunan dan pengembangan sistem pelayanan publik berbasis teknologi digital / Richardus Eko Indrajit. $\hat{A}$

3) Atang Gumawang, 2004. Merakit Komputer, Informatika Bandung.

4) Yogyakarta: Andi, 2005. Elektronika digital dan mikroprosesor / Widodo Budiharto; Sigit Firmansyah. 